\title{
11. HEAT FLOW AND THERMAL CONDUCTIVITY MEASUREMENTS, LEG 25, DEEP SEA DRILLING PROJECT
}

\author{
B. Vaughn Marshall, U. S. Geological Survey, Menlo Park, California \\ and \\ A. J. Erickson, Department of Geology, University of Georgia, Athens, Georgia
}

\section{INTRODUCTION}

A modest heat-flow program was carried out in the southwestern Indian Ocean on Leg 25 of the D/V Glomar Challenger. Three heat-flow values ranging from 0.70 to $1.03 \mu \mathrm{cal} / \mathrm{cm}^{2} \mathrm{sec}$ were obtained from Sites 242,248 , and 249; the heat-flow values are all subnormal and are comparable to nearby values obtained using standard oceanographic techniques.

\section{TEMPERATURE MEASUREMENTS}

Temperatures in the drill hole were acquired using the JOIDES downhole instrument (DHI) developed at the Woods Hole Oceanographic Institution and described by Erickson (1973). The DHI is a pressure-tight, self-contained unit powered by batteries. The temperature sensor is a thermistor located in a $0.95-\mathrm{cm}(3 / 8$ inch $)$ diameter probe about $60 \mathrm{~cm}$ (23.6 inches) below the instrument package so that it protrudes ahead of the drill bit when the DHI is emplaced at the bottom of the drill string. Thermistor resistance is converted to frequency by a variable frequency oscillator, and the frequency is recorded digitally on a magnetic drum recorder. Temperature and calibration data are recorded alternately every $4 \mathrm{sec}$ for 22 minutes. The drum size limits the amount of data that can be stored so a delaying turn-on mechanism is incorporated which provides some control for the time interval of data acquisition.

Originally it was intended that the DHI would be positioned inside the bottom of the inner core barrel, and that after a 10 to 15 minute temperature reading, a core would be obtained. Because the DHI electronics package was not rugged enough to be dropped down the drill pipe, it was lowered on the wire line immediately after a coring operation. This method was found to yield more reliable in situ temperature data because of increased instrument reliability. It is also possible that the sediment immediately ahead of the bit may be less disturbed after coring than it would be after washing, which is the time the temperature ordinarily would have been measured. This possibility was suggested by the apparent rapid approach to equilibrium of the temperatures recorded for run 3 (Figure 4 ) and run 4 (Figure 5). Lowering the DHI on line is undesirable from a drilling standpoint, however, because of the extra time it requires.

On the first run (Site 242), the latching device was attached to the extender with set screws to prevent the DHI from being pushed up into the inner core barrel. The latch did not return with the DHI but was recovered as coring continued. For the second run (Site 242), a special short length of inner barrel with a baffle inside was used. A pipe was inserted between the baffle and the top of the DHI, making it essentially impossible for the DHI to be pushed up into the inner barrel and also reducing the possibility of losing any hardware in the hole. This set-up was used successfully on all remaining runs.

\section{Site 242}

Temperature runs 1 and 2 were made at Site 242. The record for the first run (Figure 1) indicates a relatively constant temperature of $6.25^{\circ} \mathrm{C}$ after the bottom of the hole was reached. There is no indication of heating due to friction at the pull-out. These observations, coupled with the fact that the release latch on the probe came off, suggest that the probe was pushed up into the inner barrel before it could penetrate the undisturbed sediment. However, heat-flow calculations indicate that the temperature measured may be very near the ambient temperature at that depth.

The temperature record for the second run was much different (Figure 2). The temperature increased and approached an equilibrium value slowly after a short pericd of almost constant temperature. An equilibrium value must be estimated roughly from the trend of the curve. When this is done, a value of about $11.0^{\circ} \mathrm{C}$ is suggested; it is assumed that this value is within $0.5^{\circ} \mathrm{C}$ of the correct value, and therefore, the heat flow could be affected by no more than about 10 percent. The DHI probably penetrated material that had slumped to the bottom of the hole and

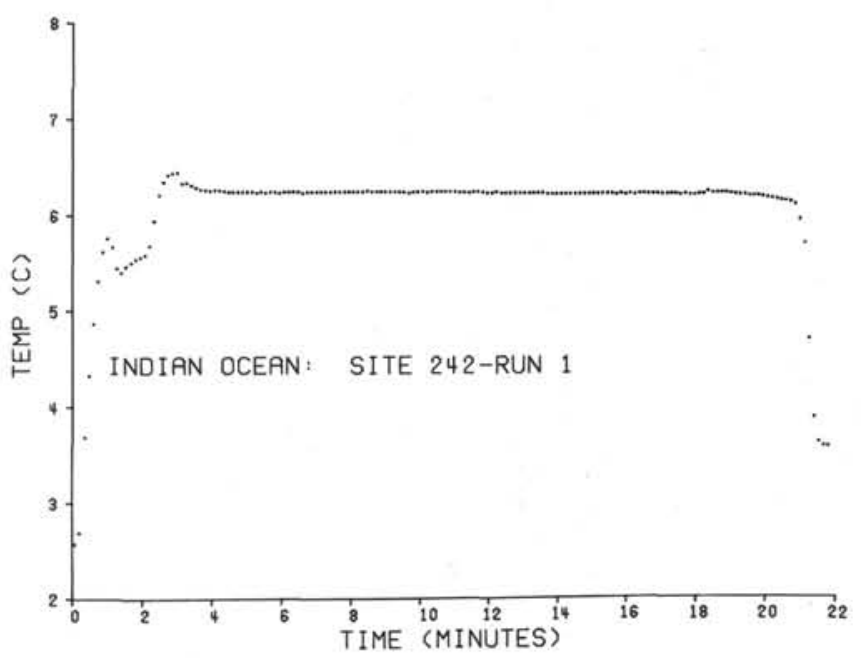

Figure 1. Temperature record for Run 1. 


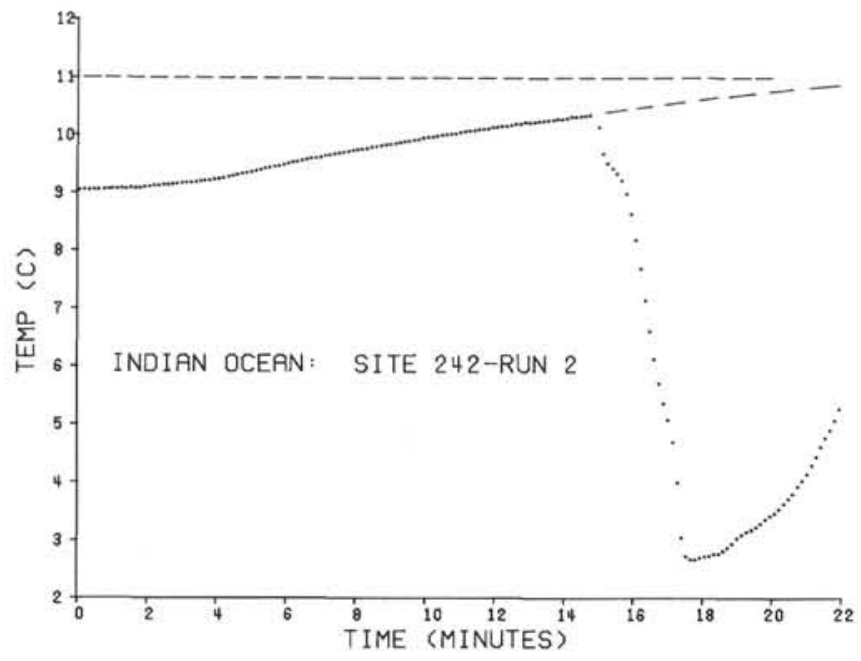

Figure 2. Temperature record for Run 2.

had not attained thermal equilibrium with the surrounding sediments. A single value of $11.51^{\circ} \mathrm{C}$ reflects a sudden increase of temperature as the DHI was lifted out of the sediment. The temperature then decreased as the DHI was raised in the hole until a minimum temperature of $2.71^{\circ} \mathrm{C}$ was recorded at the sediment-water interface. Temperatures were then measured for a short time as the DHI was raised in the pipe through the water column.

The temperature of the bottom water is often very important in heat-flow determinations. If only one sediment temperature is obtained, the bottom water temperature must be known to obtain a heat-flow value. The temperature measured by the DHI as it was lowered or raised in the drill string was that of the previously pumped drilling fluid and was probably very close to the ambient temperature of the ocean water. Simple models evaluating the reliability of bottom water temperature measurements made in the drill string do not account for the stirring or mixing action of operations in the drill string after cessation of pumping. This effect is difficult to account for quantitatively. The two temperature runs from Site 242 indicate that the reliability of such data, however, cannot be taken for granted. On run 1 , the DHI began recording very near the bottom water-sediment boundary. The first and lowest temperature recorded was $2.59^{\circ} \mathrm{C}$, and, although this may not have been measured exactly at the sediment-water interface, it is the best estimate simply because it was the lowest temperature measured. This is less than the estimated water temperature of $2.71^{\circ} \mathrm{C}$ from run 2 . Another bottom water temperature is obtained by using the potential temperature data of Wyrtki (1971). When appropriate corrections are made, a temperature of approximately $2.4^{\circ} \mathrm{C}$ is obtained. The bottom water temperature measured on run 1 was very close to Wyrtki's value; however, the latter was used for heat-flow calculations simply because it represented the more stable temperature at that depth. This criterion was used in selecting the bottom water temperatures at the other two sites, also. Temperature data for Site 242 are presented with data from the other two sites in Figure 3 and Table 1.

\section{Site 248}

Sediment temperature was measured once at Site 248 at 130 meters (Figure 4). The record clearly shows higher values at penetration into the bottom and pull-out at the end. The temperatures measured at the bottom increased with time. Superimposed on this is a variation, possibly due to movement of the probe; there were swells of at least 3 meters at the sea surface. Because of this variation, the shape of the general trend is not clearly defined, and the highest value of $6.50^{\circ} \mathrm{C}$ is taken as a reasonable, but possibly low, estimate of the sediment temperature.

The temperature record indicates a bottom water temperature of $0.69^{\circ} \mathrm{C}$. Wyrtki's (1971) data yield a lower limit of about $0.9^{\circ} \mathrm{C}$. The value of $0.69^{\circ} \mathrm{C}$ was used for heat-flow calculations.

\section{Site 249}

The water depth at Site 249 was only 2088 meters. This may partially explain the configuration of the temperature record as shown in Figure 5. The DHI turned on near the bit while it was still being lowered in the core barrel. After a check to make sure that the core barrel had latched into the bit, the bottom hole assembly was lowered to the bottom. This can be seen with the first temperature rise at point number 6 , followed by the beginning of a cooling curve. The bit and probe were then raised one meter, and another increase was followed by a cooling curve. The temperature record suggests that the temperature of the drilling fluid, and the temperature of the combination of drilling fluid and slumped material immediately above the bottom of the hole, was slightly warmer than the sediments at this depth $(140 \mathrm{~m})$ a physical explanation for this is not

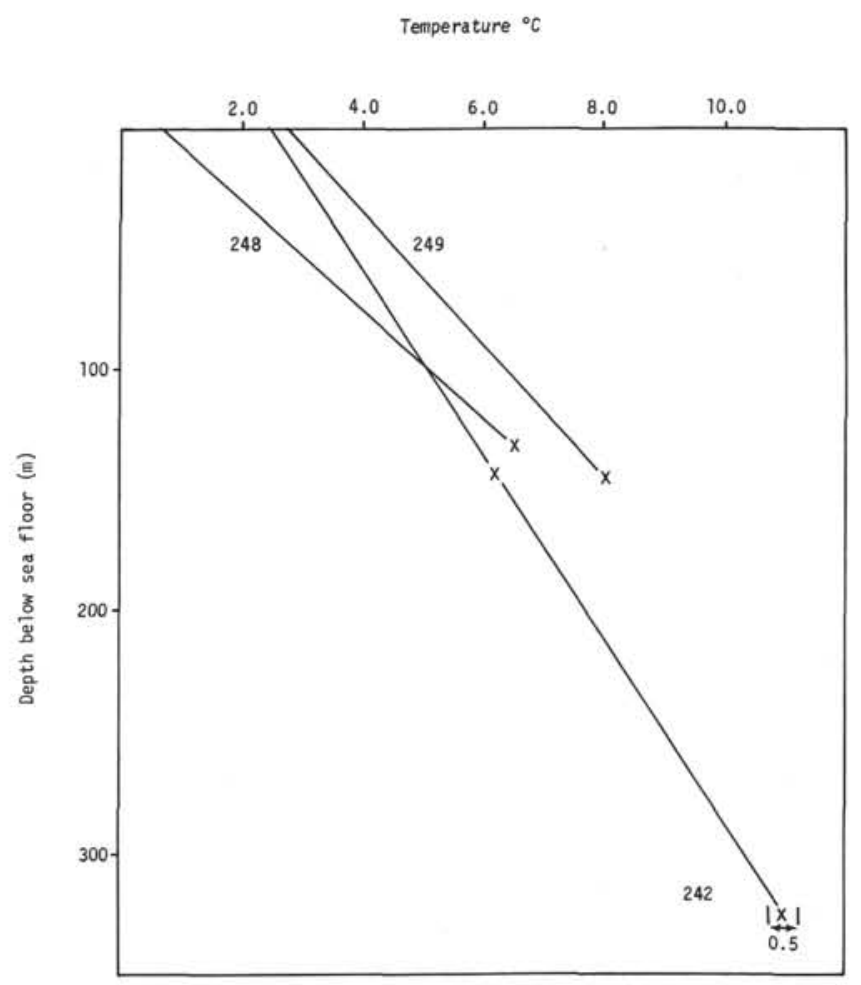

Figure 3. Sediment temperature profiles for heat-flow sites. 
TABLE 1

Bottom Water and Sediment Temperatures

\begin{tabular}{|c|c|c|c|c|c|c|}
\hline \multirow{2}{*}{$\frac{\text { Run }}{1}$} & \multirow{2}{*}{$\begin{array}{l}\text { Site } \\
242\end{array}$} & \multirow{2}{*}{$\begin{array}{c}\begin{array}{c}\text { Water } \\
\text { Depth } \\
(\mathrm{m})\end{array} \\
2275\end{array}$} & \multicolumn{2}{|c|}{$\frac{\text { Water Temperature }\left({ }^{\circ} \mathrm{C}\right)}{\text { DHI Wyrtki }(1971)}$} & \multirow{2}{*}{$\begin{array}{c}\begin{array}{c}\text { Sub- } \\
\text { Bottom } \\
\text { Depth } \\
\text { (m) }\end{array} \\
141\end{array}$} & \multirow{2}{*}{$\frac{\begin{array}{c}\text { Sediments } \\
\left({ }^{\circ} \mathrm{C}\right)\end{array}}{6.25}$} \\
\hline & & & 2.59 & 2.4 & & \\
\hline 2 & 242 & & 2.71 & 2.4 & 317 & $\simeq 11.0$ \\
\hline 3 & 248 & 4994 & 0.69 & $0.9<\theta<1.4$ & 130 & 6.50 \\
\hline 4 & 249 & 2088 & 3.00 & 2.8 & 140 & $\simeq 8.00$ \\
\hline
\end{tabular}

obvious. The cooling curve described by the temperatures in the bottom suggests a combination of the dissipation of the frictional heat and a rapid approach to thermal equilibrium. The lowest value of $8.00^{\circ} \mathrm{C}$ is probably within $\pm 0.25^{\circ} \mathrm{C}$ of the ambient temperatures.

Wyrtki's (1971) value of approximately $2.8^{\circ} \mathrm{C}$ is considered more accurate than the measured bottom water temperature, $3.0^{\circ} \mathrm{C}$.

\section{THERMAL CONDUCTIVITY}

\section{Method}

Thermal conductivity of the sediments was measured aboard ship. The tests, run within a few hours after recovery of the core, were made by the needle-probe method (Von Herzen and Maxwell, 1959), which makes use of the approximation (for short periods of time) of a heater circuit in a hypodermic needle to an infinite line source. The temperature rise at the source, measured by a thermistor in the probe, is then related to the thermal conductivity of the surrounding medium and the logarithm of time by heat-conduction theory. The theory is covered in several publications (i.e., Lachenbruch, 1957; Carslaw and Jaeger, 1959; and Von Herzen and Maxwell, 1959). The data were reduced by digitizing the strip-chart recordings of temperature versus time made aboard the $\mathrm{D} / \mathrm{V}$ Glomar Challenger. The pairs of time-temperature data

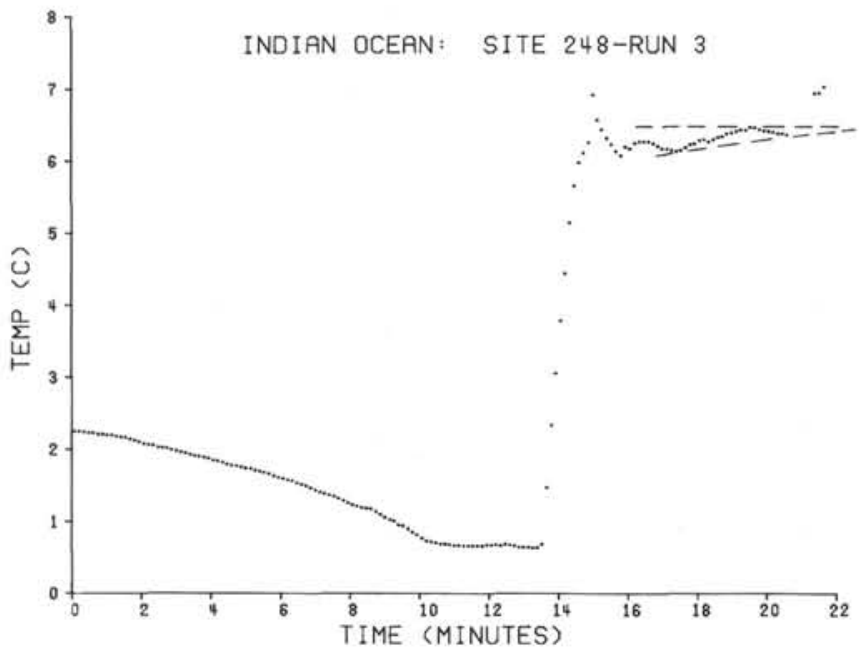

Figure 4. Temperature record for Run 3.

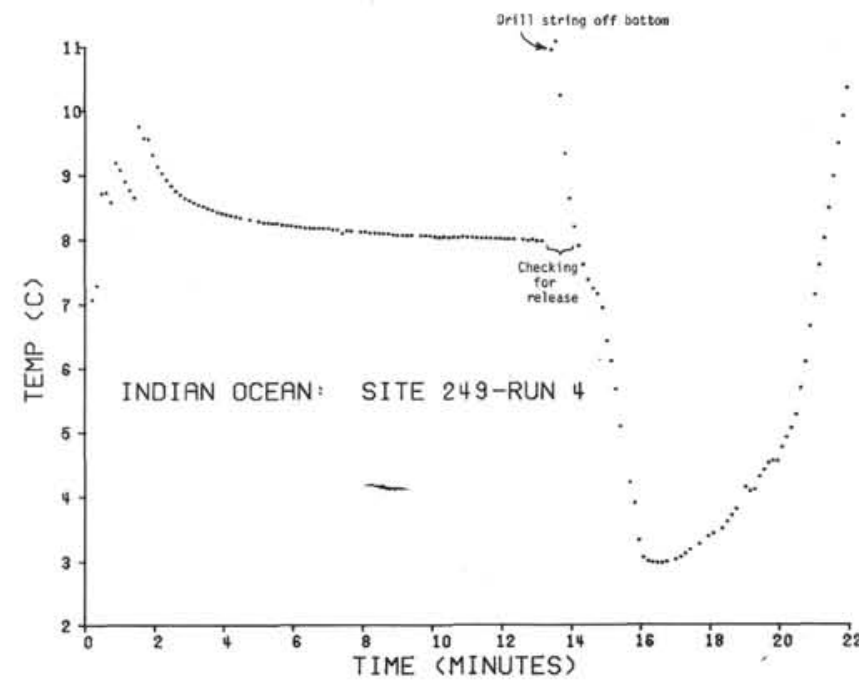

Figure 5. Temperature record for Run 4.

were then fitted by least-squares criteria to a curve of the form

$$
\theta=A+B t+C 1 \mathrm{nt}
$$

where $A, B$, and $C$ are coefficients determined using a nonlinear regression program.

The temperature and pressure of the sediments when tested aboard ship were different from the in situ values. Using the suggestions of Ratcliffe (1960), corrections were applied using equation 2 .

$K_{\mathrm{CORR}}=K_{\mathrm{OBS}}\left[1.0+\left(\frac{W+p H}{182900}\right)+\left(\frac{T_{W}+H G-T_{\mathrm{LAB}}}{400}\right)\right]$

where

$$
\begin{array}{ll}
W & =\text { water depth }(\mathrm{m}) \\
p & =\text { mean sediment density }(\mathrm{gm} / \mathrm{cc}) \\
H & =\text { drill-hole depth }(\mathrm{m}) \\
T_{W} & =\text { bottom water temperature }\left({ }^{\circ} \mathrm{C}\right) \\
G & =\text { mean geothermal gradient }\left({ }^{\circ} \mathrm{C} / \mathrm{m}\right) \\
T_{\mathrm{LAB}} & =\text { laboratory ambient sediment temperature } \\
& \left({ }^{\circ} \mathrm{C}\right)
\end{array}
$$

The values of these parameters used for reduction of the data at each site are presented in Table 2 . Wherever

TABLE 2

Site Parameters Used for Environmental Corrections

\begin{tabular}{lcccc}
\hline Site & $\begin{array}{c}\text { Water Depth } \\
(\mathrm{m})\end{array}$ & $\begin{array}{c}\text { Bottom Water } \\
\text { Temperature } \\
\left({ }^{\circ} \mathrm{C}\right)\end{array}$ & $\begin{array}{c}\text { Geothermal } \\
\text { Gradient } \\
\left({ }^{\circ} \mathrm{C} / \mathrm{m}\right)\end{array}$ & $\begin{array}{c}\text { Sediment Density } \\
(\mathrm{g} / \mathrm{cc})\end{array}$ \\
\hline 241 & 4054 & $1.50^{\mathrm{a}}$ & 0.0608 & 1.70 \\
242 & 2275 & 4.45 & 0.0270 & 1.85 \\
245 & 4857 & $1.30^{\mathrm{a}}$ & $0.0935^{\mathrm{a}}$ & 1.99 \\
246 & 1030 & $7.00^{\mathrm{a}}$ & $0.0741^{\mathrm{a}}$ & 2.09 \\
248 & 4994 & 0.69 & 0.0434 & 1.80 \\
249 & 2088 & 2.84 & 00357 & 1.80 \\
\hline
\end{tabular}

aEstimated from surrounding hydrographic and heat-flow data. 
possible, these parameters have been determined using downhole temperature data $\left(T_{W}, G\right)$, physical property data $(p)$, and bathymetric data $(W)$ for each site. Because preliminary temperature data were used, the final values used for bottom water temperature at Sites 242 and 249 (Table 1) were slightly different. Inasmuch as these differences would result in corrections to those conductivities of approximately 0.5 percent or less, further corrections were not made. Where one or more of the parameters was not determined, values were estimated using other available data, such as hydrographic data for bottom water temperature and regional heat-flow values for the geothermal gradient. Generally, the environmental corrections are only a few percent, and the uncertainty in these parameters is negligible.

\section{Data}

Thermal conductivity values for all Leg 25 sites are listed in Table 3. Plots of thermal conductivity against various parameters are shown in Figures 6, 7, and 8. A total of 118

TABLE 3

Thermal Conductivity Values for Leg 25 - Western Indian Ocean

\begin{tabular}{|c|c|c|c|c|c|c|c|c|}
\hline Site & $\begin{array}{l}\text { Depth } \\
\text { (m) }\end{array}$ & $\mathrm{K}^{\mathrm{a}}$ & Site & $\begin{array}{l}\text { Depth } \\
\text { (m) }\end{array}$ & $\mathrm{K}^{\mathrm{a}}$ & Site & $\begin{array}{l}\text { Depth } \\
\text { (m) }\end{array}$ & $\mathrm{K}^{\mathrm{a}}$ \\
\hline 241 & 12 & 2.37 & 242 & 153 & 2.65 & $245 \mathrm{~A}$ & 147 & 2.71 \\
\hline 241 & 13 & 2.30 & 242 & 154 & 2.65 & $245 \mathrm{~A}$ & 147 & 2.92 \\
\hline 241 & 13 & 2.13 & 242 & 241 & 2.97 & 245 & 161 & 3.08 \\
\hline 241 & 61 & 2.85 & 242 & 242 & 2.66 & 245 & 161 & 2.63 \\
\hline 241 & 61 & 2.16 & 242 & 316 & 2.12 & 245 & 166 & 2.68 \\
\hline 241 & 62 & 2.51 & 242 & 316 & 2.75 & 245 & 210 & 3.44 \\
\hline 241 & 112 & 2.54 & 242 & 317 & 2.57 & 245 & 211 & 3.27 \\
\hline 241 & 112 & 2.75 & 242 & 411 & 2.91 & 245 & 211 & 3.40 \\
\hline 241 & 114 & 2.41 & 242 & 412 & 2.85 & 245 & 247 & 2.70 \\
\hline 241 & 148 & 2.24 & 242 & 487 & 3.33 & 245 & 247 & 3.46 \\
\hline 241 & 149 & 2.42 & 242 & 488 & 3.47 & 245 & 284 & 3.60 \\
\hline 241 & 149 & 2.51 & 242 & 488 & 3.18 & 245 & 333 & 3.26 \\
\hline 241 & 185 & 2.90 & 242 & 557 & 2.80 & 245 & 333 & 3.51 \\
\hline 241 & 185 & 2.56 & 242 & 557 & 3.37 & 246 & 168 & 3.47 \\
\hline 241 & 186 & 2.54 & 242 & 558 & 3.22 & 246 & 170 & 3.48 \\
\hline 241 & 261 & 3.25 & 242 & 606 & 3.26 & 248 & 126 & 2.25 \\
\hline 241 & 261 & 2.63 & 242 & 606 & 3.05 & 248 & 126 & 2.37 \\
\hline 241 & 262 & 2.95 & 242 & 610 & 3.38 & 248 & 362 & 2.75 \\
\hline 241 & 403 & 3.04 & 242 & 611 & 3.46 & 248 & 363 & 2.47 \\
\hline 241 & 403 & 2.70 & 242 & 628 & 3.47 & 248 & 396 & 2.78 \\
\hline 241 & 532 & 2.50 & 242 & 629 & 3.30 & 248 & 396 & 2.69 \\
\hline 241 & 533 & 2.60 & 242 & 638 & 3.39 & 249 & 21 & 2.67 \\
\hline 241 & 584 & 3.58 & 242 & 638 & 3.45 & 249 & 29 & 2.63 \\
\hline 241 & 585 & 2.66 & 242 & 646 & 3.29 & 249 & 49 & 2.64 \\
\hline 241 & 585 & 2.62 & 242 & 647 & 3.72 & 249 & 71 & 2.65 \\
\hline 241 & 632 & 2.51 & 242 & 647 & 3.47 & 249 & 89 & 2.71 \\
\hline 241 & 751 & 2.52 & 242 & 651 & 3.57 & 249 & 98 & 2.62 \\
\hline 241 & 752 & 2.82 & 242 & 651 & 3.60 & 249 & 112 & 2.70 \\
\hline 241 & 752 & 2.70 & 245 & 9 & 1.65 & 249 & 117 & 2.88 \\
\hline 241 & 840 & 2.56 & 245 & 13 & 1.88 & 249 & 136 & 2.89 \\
\hline 241 & 841 & 2.93 & 245 & 14 & 1.75 & 249 & 155 & 3.18 \\
\hline 241 & 981 & 3.09 & $245 \mathrm{~A}$ & 30 & 1.99 & 249 & 183 & 2.75 \\
\hline 241 & 981 & 2.97 & $245 \mathrm{~A}$ & 30 & 2.10 & 249 & 203 & 2.79 \\
\hline 241 & 981 & 2.98 & $245 \mathrm{~A}$ & 30 & 2.05 & 249 & 223 & 2.69 \\
\hline 242 & 57 & 2.52 & $245 \mathrm{~A}$ & 60 & 2.01 & 249 & 242 & 2.73 \\
\hline 242 & 57 & 2.43 & $245 \mathrm{~A}$ & 61 & 2.08 & 249 & 261 & 2.95 \\
\hline 242 & 58 & 2.45 & $245 \mathrm{~A}$ & 78 & 2.00 & 249 & 281 & 2.90 \\
\hline 242 & 136 & 2.64 & $245 \mathrm{~A}$ & 79 & 2.24 & 249 & 289 & 2.57 \\
\hline 242 & 136 & 2.66 & 245 & 126 & 2.73 & & & \\
\hline 242 & 137 & 2.65 & 245 & 126 & 2.82 & & & \\
\hline
\end{tabular}

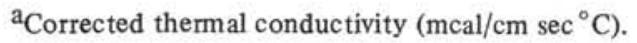

thermal conductivity values were determined. The histogram (Figure 6) shows several peaks, some of them minor and of doubtful significance. The general distribution, however, is bimodal. The strongest peak lies between 2.6 and $2.7 \mathrm{mcal} / \mathrm{cm} \mathrm{sec}{ }^{\circ} \mathrm{C}$. The second mode is not as well defined but consists of a double peaked rise between 3.2 and $3.5 \mathrm{mcal} / \mathrm{cm} \mathrm{sec}{ }^{\circ} \mathrm{C}$. Almost all of the present data are from much deeper cores (subbottom depth) than those obtained from the gravity and piston corers used in conventional oceanic operations, and the bulk densities and thermal conductivities are generally higher.

The present work provides a fairly large number of higher conductivity values and therefore yields some detail in the distribution of these values. The possible significance of this detail, however, is obscure. The thermal conductivity tests were run before the cores were split open, making it very difficult to locate them at the least disturbed portions of the cores. Other physical property tests were run and samples taken at selected points after the core was split open, but seldom were these located at the same position or very close to thermal conductivity test locations. Most of the cores were run through the GRAPE (gamma ray attenuation and porosity evaluator) device to measure the bulk density. The bulk density data from the GRAPE device available for this report were the field values. These and bulk density values obtained from samples were used to obtain average values for different lithologic units. Thermal conductivity values were also averaged over these lithologic units to obtain data used in Figure 8. These are not exact relationships between bulk density and thermal conductivity, but they do suggest a general relationship for the sediments encountered and measured. Thermal conductivity is more often plotted against water content, but, inasmuch as bulk density and water content are generally inversely related, the distribution of points in Figure 8 is to be expected.

\section{HEAT FLOW}

Heat flow was determined using the measured geothermal gradients and the harmonic average of thermal conductivity over the same intervals (Table 4). The gradient and heat flow listed for run 2 are for the interval 141 to 317 meters. For the other three runs, it was necessary to use the bottom water temperatures. The heat-flow values from the two gradient intervals of Site 242 were averaged to yield $0.70 \mathrm{HFU}\left(1 \mathrm{HFU}=10^{-6} \mathrm{cal} / \mathrm{cm}^{2} \mathrm{sec}\right)$. This is very close to the 0.72 HFU measured at station V19-102 (Von Herzen and Langseth, 1965), $142 \mathrm{~km}$ to the southwest, and only 273 meters shallower than Site 242 . The value at station V19-102 was obtained with a modified piston corer, with only one thermistor penetrating. Site 242 , on the lee side of the Davie Ridge in the Mozambique Channel, is in an area of predominantly pelagic sedimentation. Basement was not reached with drilling, but the sedimentary record suggests apparent tectonic quiescence for at least the last 40 m.y. The sedimentation rate of $2 \mathrm{~cm}$ per thousand years, although high for pelagic sediments, is not sufficient to affect the heat flow appreciably (Von Herzen and Uyeda, 1963). The site location on the ridge is such that the 


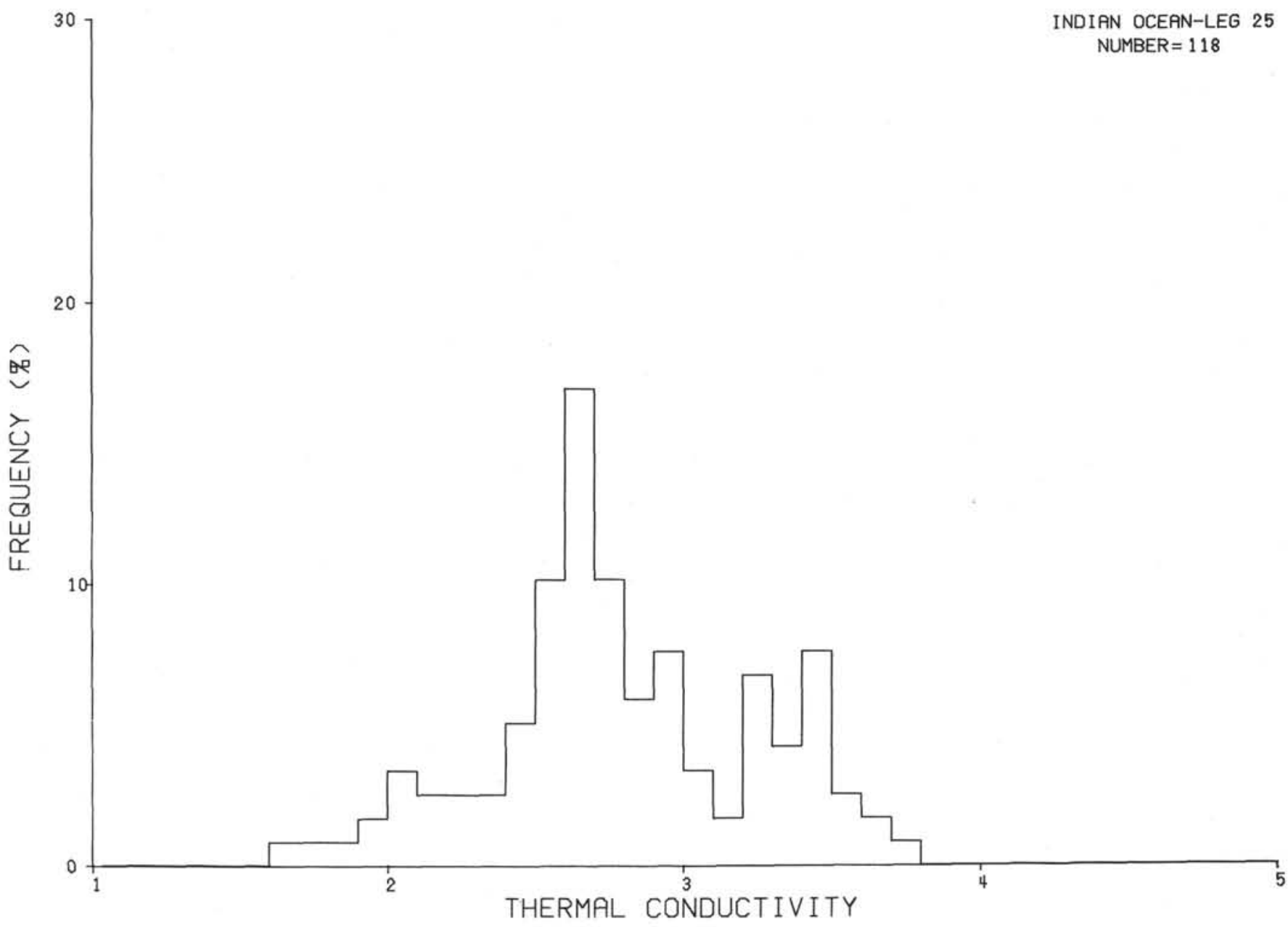

Figure 6. Histogram of Leg 25 thermal conductivity measurements.

TABLE 4

Summary of Heat-Flow Values

\begin{tabular}{cccccccc}
\hline Run & Site & $\begin{array}{c}\text { Latitude } \\
(\mathrm{S})\end{array}$ & $\begin{array}{c}\text { Longitude } \\
(\mathrm{E})\end{array}$ & $\begin{array}{c}\text { Gradient } \\
\left({ }^{\circ} \mathrm{C} / \mathrm{km}\right)\end{array}$ & $\begin{array}{c}\mathrm{K}^{\mathrm{a}} \\
\left(\mathrm{mcal}^{\circ} \mathrm{cm}\right) \\
\left.\sec ^{\circ} \mathrm{C}\right)\end{array}$ & $\begin{array}{c}\text { Heat Flow } \\
(\mathrm{HFU})\end{array}$ \\
\hline 1 & 242 & $15^{\circ} 50.65^{\prime}$ & $41^{\circ} 49.23^{\prime}$ & 27.3 & 2.54 & 0.69 & \\
& & & & & & & 0.70 \\
2 & 242 & & & 27.0 & 2.61 & 0.70 & \\
3 & 248 & $29^{\circ} 31.78^{\prime}$ & $37^{\circ} 28.48^{\prime}$ & 44.6 & 2.31 & & 1.03 \\
4 & 249 & $29^{\circ} 56.99^{\prime}$ & $36^{\circ} 04.62^{\prime}$ & 37.1 & 2.68 & & 1.00 \\
\hline
\end{tabular}

${ }^{\mathrm{a}} \mathrm{Harmonic}$ mean of measured thermal conductivities.

topography would not have significantly affected the heat flow (Lachenbruch, 1969).

Sites 248 and 249 were located in the Mozambique Basin and on the Mozambique Ridge, respectively. The difference in depths at the two sites is about 2900 meters (Table 1). Their heat-flow values of $1.03 \mathrm{HFU}$ and 1.00 HFU are in good agreement. The nearest oceanographic heat-flow value is at station LSDA-50 (Von Herzen and Langseth, 1965), where $1.00 \mathrm{HFU}$ was measured. Other nearby stations are LSDA-51, LSDA-52, and V19-112, where $2.22,0.82$, and $1.20 \mathrm{HFU}$ were measured, respectively. If the $2.22 \mathrm{HFU}$ value is disregarded and the other three averaged, the result, $1.01 \mathrm{HFU}$, is essentially the same as the average of 1.02 HFU for Site 248 and Site 249 . The scatter of heat-flow values may be due to local effects, while $1.01 \mathrm{HFU}$ is probably close to the regional trend.

Site 249 was located in a restricted deposition basin not far from the edge of the ridge. However, using the method of Lachenbruch (1969) to evaluate possible topographic corrections and that of Lachenbruch and Marshall (1966) to investigate possible effects of the deposition basin, resulted in heat-flow corrections less than the error expected from measurement of the heat flow. Since the sedimentation rate, $1.4 \mathrm{~cm} / 10^{3} \mathrm{yr}$, is also insufficient to meaningfully reduce the heat flow, the value of $1.00 \mathrm{HFU}$ is considered representative of the regional values.

Often, $5^{\circ} \times 5^{\circ}$ squares are used in setting up a map grid for presentation of heat-flow data. The present measurement would affect Langseth and Taylor's (1967) grid by strengthening the value of $0.72 \mathrm{HFU}$ for the square west of central Madagascar and changing the value from $1.32 \mathrm{HFU}$ to an average of $1.12 \mathrm{HFU}$ for the area between $25^{\circ}-30^{\circ}$ south Latitude and $35^{\circ}-40^{\circ}$ east Longitude. The value for the latter square is then close to those of 1.14 HFU and 1.16 HFU for the areas immediately east and northeast of it. 


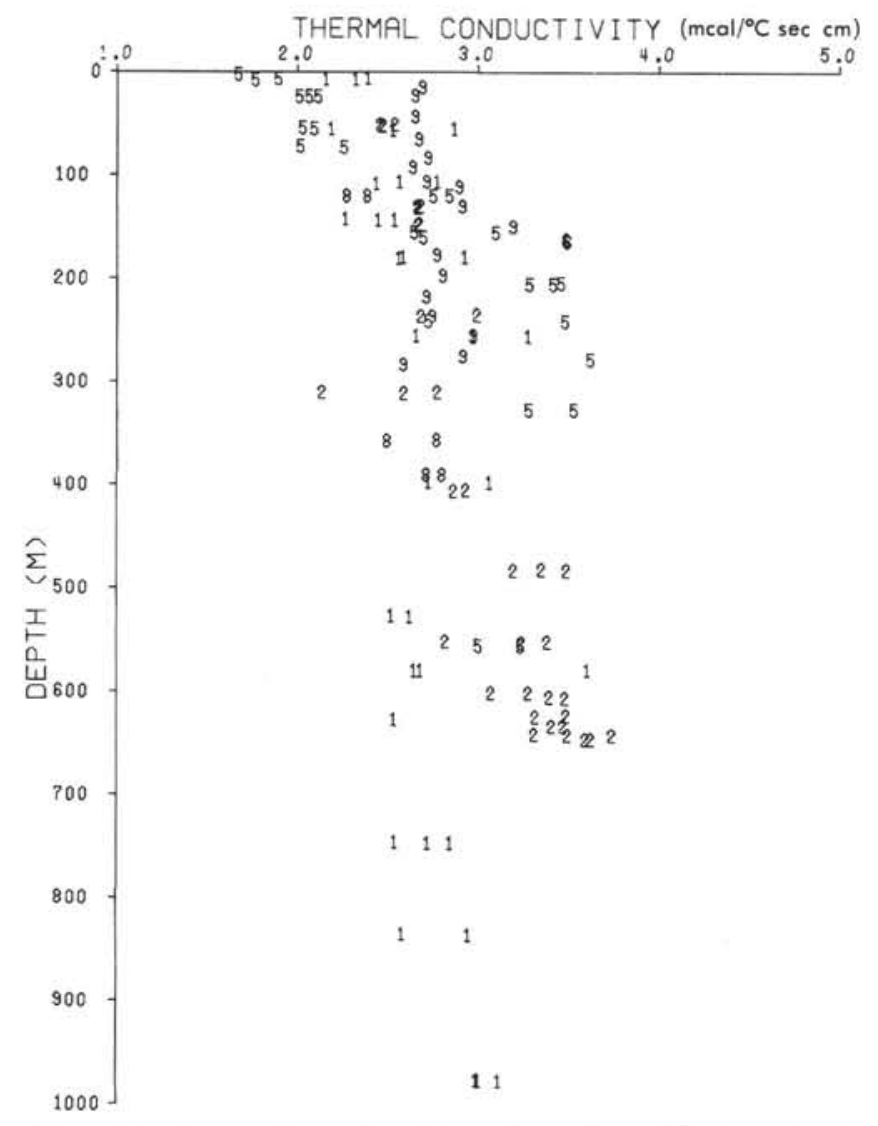

Figure 7. Thermal conductivity from Leg 25 sites. Each point number represents the last digit of the number of the site it belongs to (241-249).

\section{ACKNOWLEDGMENTS}

We are grateful to the crew of the Glomar Challenger for their help and suggestions and particularly to Lloyd Russill who kept an ailing DHI running. Ted Gustafson provided valuable help in operating the DHI, and Arthur $\mathrm{H}$. Lachenbruch and John H. Sass were extremely helpful with suggestions and comments on the manuscript.

\section{REFERENCES}

Carslaw, H. S. and Jaeger, J. C., 1959. Conduction of heat in solids: Oxford (Clarendon Press).

Erickson, A., 1973. Initial report on downhole temperature and shipboard thermal conductivity measurements, Leg 19, Deep Sea Drilling Project. In Creager, J. S., Scholl, D. W., et al., Initial Reports of the Deep Sea Drilling Project, Volume XIX: Washington (U.S. Government Printing Office), $643 \mathrm{pp}$.

Lachenbruch, A. H., 1957. A probe for measurement of thermal conductivity of frozen soils in place: Am. Geophys. Union Trans., v. 38, p. 691. 1969. The effect of two-dimensional topography on superficial thermal gradients: U. S. Geol. Survey Bull. 1203-E, p. E1-E86.

Lachenbruch, A. H. and Marshall, B. V., 1966. Heat flow through the Arctic Ocean floor: The Canada Basin-Alpha Rise boundary: J. Geophys. Res., v. 71, p. 1223.

Langseth, M. G. and Taylor, P. T., 1967. Recent heat-flow measurements in the Indian Ocean: J. Geophys. Res., v. 72 , p. 6249.

Ratcliffe, E. H., 1960. The thermal conductivities of ocean sediments: J. Geophys. Res., v. 65, p. 1535.

Von Herzen, R. and Maxwell, A. E., 1959. The measurement of thermal conductivity of deep-sea sediments by a needle-probe method: J. Geophys. Res., v. 64 , p. 1557.

Von Herzen, R. and Langseth, M. G., 1965. Present status of oceanic heatflow measurements. In Ahrens, L. H., et al., (Eds.) Physics and chemistry of the earth: London (Pergamon Press), v. 6.

Von Herzen, R. and Uyeda, S., 1963. Heat flow through the eastern Pacific Ocean floor: J. Geophys. Res., v. 68, p. 4219.

Wyrtki, K., 1971. Oceanographic Atlas of the International Indian Ocean Expedition: Washington (U. S. Government Printing Office), $531 \mathrm{pp}$. 


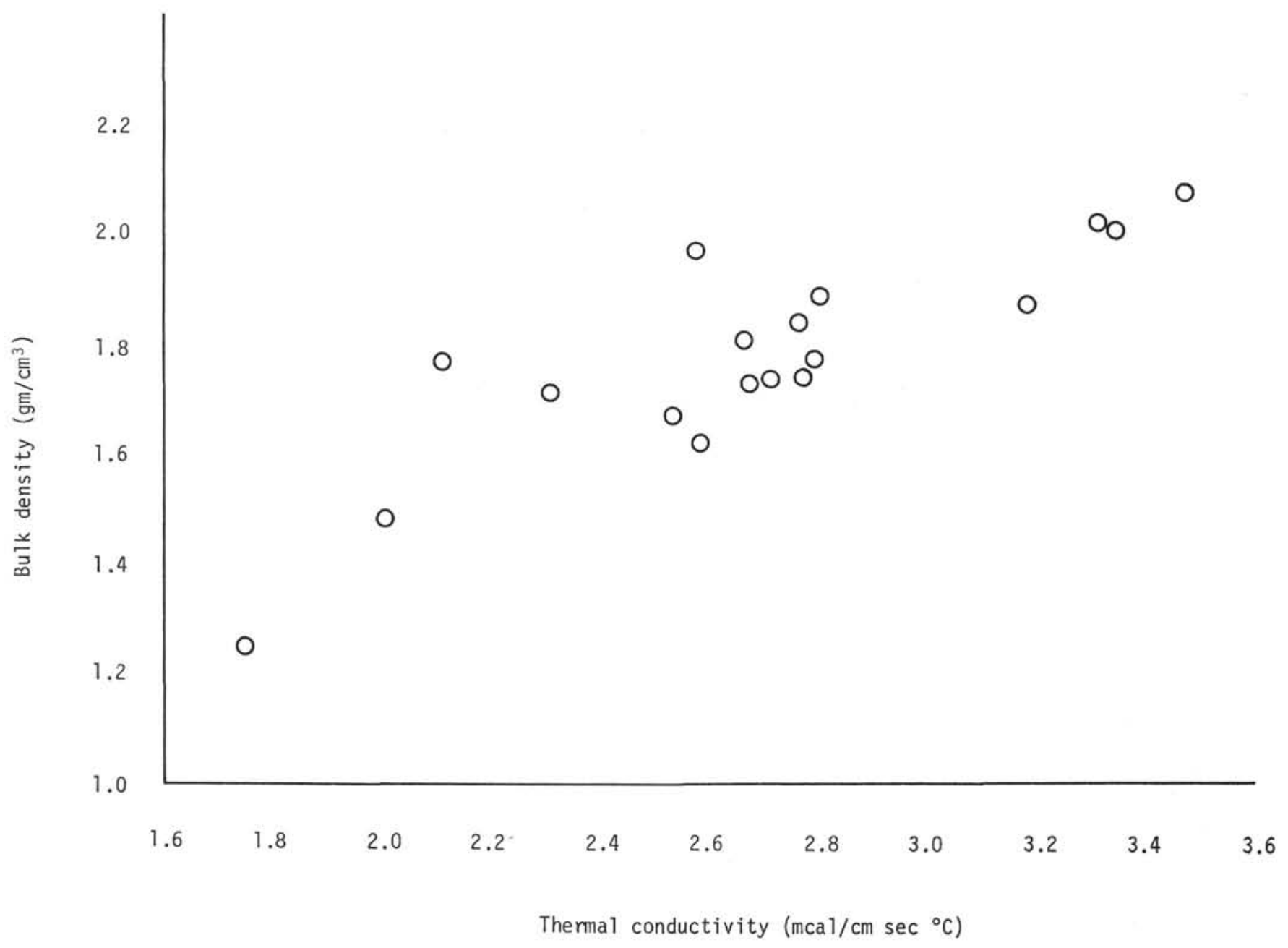

Figure 8. Thermal conductivity versus bulk density. Values are averages of lithology units tested. 